\title{
因HAD
}

ISSN-L: 2530-5115

(c) (1)(2)

DOI: http://doi.org/10.22585/hospdomic.v2i4.52

\section{Dos películas de nutrición artificial rodadas en el hospital Ramón y Cajal hace cuarenta años}

\section{Two films of artificial nutrition filmed at the Ramón y Cajal hospital forty years ago}

Jesús M. Culebras'

1. De la Real Academia de Medicina de Valladolid y del IBIOMED, Universidad de León, España.

Correspondencia/Correspondence

Jesús M. Culebras

Universidad de León, IBIOMED, León, España

doctorculebras@gmail.com

Recibido/Received

30.07.2018

Aceptado/Accepted

26.08.2018
Conflicto de Intereses/Competing interest No existe ningún conflictico de interés en la presente carta.

CÓMO CITAR ESTE TRABAJO | HOW TO CITE THIS PAPER

Culebras JM. Dos películas de nutrición artificial rodadas en el hospital Ramón y Cajal hace cuarenta años. Hosp Domic. 2018;2(4): 179-81. 


\section{Sra. Directora.}

He leído con mucho interés y satisfacción el trabajo de investigación de Garcia y Mauriz (1) en el que recuperan dos películas científicas, rodadas por mí en $16 \mathrm{~mm}$ hace cuarenta años. En los años setenta del siglo pasado era muy atractivo hacer películas en este formato aunque, lamentablemente luego tenían poquísima difusión. Al no haber medios para copiarlas solo se podían visualizar cuando se organizaba una proyección. Estas dos películas, que en el artículo aludido se consideran pioneras en nutrición artificial, fueron proyectadas en la Primera Reunión de SENPE en Bilbao en 1979 y en el Primer Congreso Europeo de Nutrición Parenteral y Enteral (ESPEN) en Estocolmo, en 1980; ver figura 1. Luego se visionaron de nuevo en la Semana de Cine Médico de Motril de 1980. En total pudo haber unos doscientos espectadores, siendo optimistas en el cálculo. Por ello las películas han pasado absolutamente desapercibidas en la historia científica de la nutrición artificial. Ars non habet inimicum nisi ignorantem (La ciencia no tiene más enemigo que el ignorante).

Figura 2. Carta de aceptación de la película: Artificial gut (Ambulatory parenteral nutrition) en el primer congreso de ESPEN en Estocolmo en 1979.

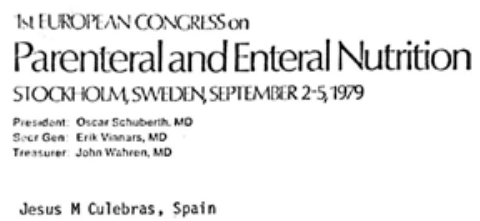

MERTORANCONGRESSON

Parenteral and Enteral Nutrition SIOCKH HOLM, SWEDEN SEPIEMBRR 2-5, 1979

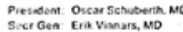

Secresenter John Wather, Mo

Jesus M Culebras, Spain

19790618

Dear Dr.

The Organizing Committee of the First European Congress on Parenteral and Enteral Nutrition has now revieved the approximately advising you that your abstract (no. 110 ) entitled:

ARTIFICIAL GUT (AMBULATORY PARENTERAL. NUTRITION)

has been accepted for fila presentation in the programe of the Congress. In a few weeks the Preliminary Scientific Programe will be mailed to all authors and partic

You are reninded that the time for your presentation is limited. Unless You are reminded that the three weeks, we shall assume that you will be we hear to the contrary withe your paper,

Looking forward to seeing you in Stockholm.

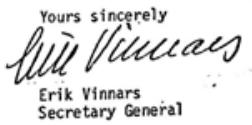
Erik Vinnars
Secretary General

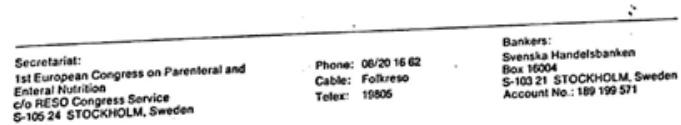


Los medios de comunicación han cambiado de forma inimaginable. Hoy se puede copiar todo, se visualiza lo grabado por Internet una y mil veces, se puede guardar... Incluso la filmación es mucho mas sencilla y económica que cuando se hacia con películas de emulsión de plata.

Volviendo a las películas que han recuperado Garcia y Mauriz, es interesante ver que hace cuarenta años estos temas ya eran de interés y se trataban en los foros de nutrición artificial. Hoy siguen siendo de máxima actualidad, habiendo variado poco.

Quiero añadir a lo aportado en el artículo el diploma que una de las películas recibió en la IX Semana del Cine Medico de Motril (ver figura 2). Ha aparecido entre otros documentos muy antiguos. Me alegro de haberlo conseguido porque, lamentablemente, este certamen científico de Motril ha dejado de celebrarse y en el ayuntamiento de Motril no tienen, o no la quieren facilitar, la información de lo acontecido en aquella época.

Reitero mi agradecimiento a Garcia y Mauriz por su bonito trabajo.

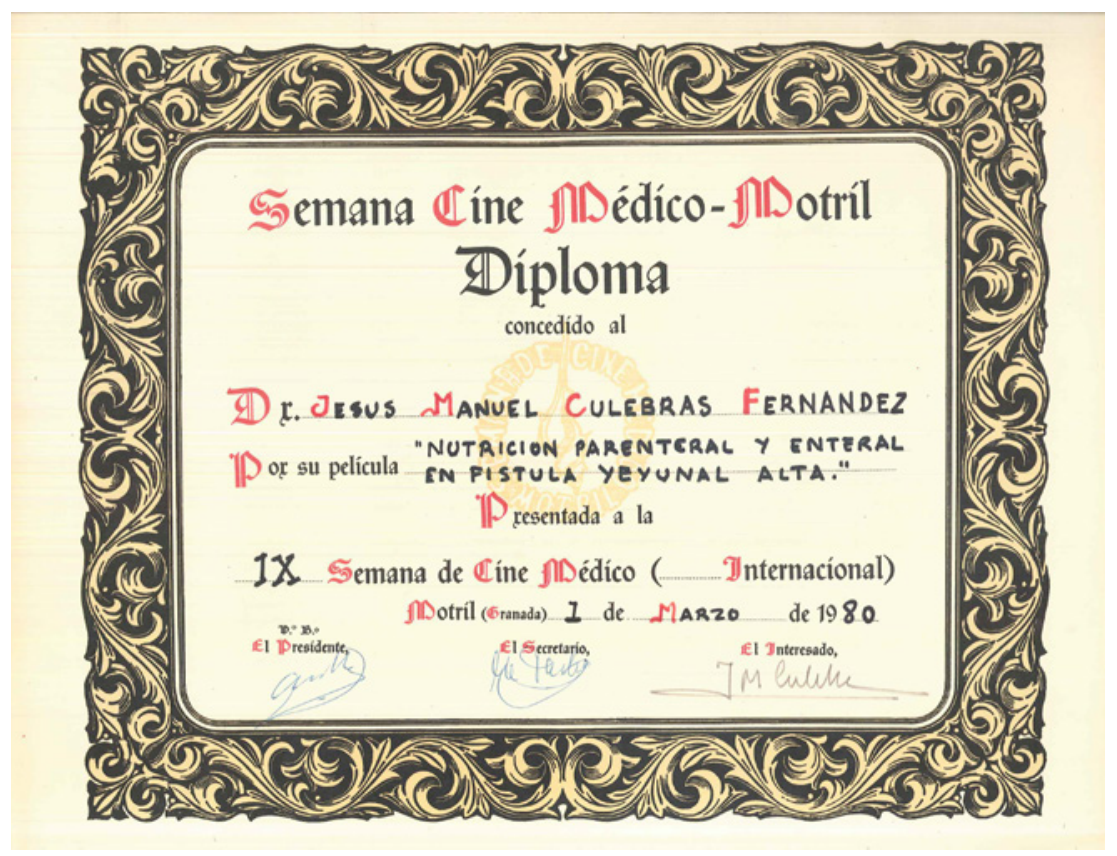

\section{BIBLIOGRAFÍA}

1. Garcia Garcia R. Mauriz Gutierrez JL. Dos películas filmadas en el hospital Ramón y Cajal en 1978, pioneras de la nutrición artificial en España. Hosp Domic. 2018;2(3):117-27. DOI: 10.22585/hospdomic.v2i3.49 